\title{
HEAT TRANSFER CRISIS ON SINTERED POROUS SURFACES - EXPERIMENTAL INVESTIGATIONS
}

\begin{abstract}
Tadeusz Michal Wojcik ${ }^{1}$
Abstract: There were presented the results of theoretical analysis of boiling heat transfer on heating surfaces covered with thin-layered capillary porous structures. The paper discussed the results of experimental investigations into intralayer boiling crisis and accompanying phenomena. It was observed that the structural parameters of the porous covering affected the course of the process. Hysteresis phenomenon manifested itself when the heat flux initiating intralayer heat crisis was reached. The crisis mechanism hypotheses, the description of which was available in literature, were discussed.
\end{abstract}

\section{INTRODUCTION}

Boiling heat transfer enhancement counts among major issues in modern thermal engineering. Cooling high integrity scale circuits and space and nuclear technology systems requires the application of highly effective and reliable cooling systems. Capillary-porous structures (CPS) as heating surface coverings offer significant boiling heat transfer enhancement. It was confirmed by investigation results available in publications. The vast literature on the subject does not report uniform outlook on the process mechanism in spite of numerous theoretical and experimental works.

The diversity of structures being manufactured results in a variety of boiling crisis phenomena. Also the very notion of boiling crisis has been defined in an ambiguous manner. Boiling crisis in porous coverings cannot be understood in the same way as in case of a smooth surface. The authors studying boiling mechanism quote "intralayer crisis" [1], "filling a structure with vapour" [2], "vapour layer appearance on the outer porous covering surface" [3], etc. Thus, the definitions of nucleate boiling crisis in porous covering demonstrate significant divergence.

Three characteristic phenomena can be observed in porous layer boiling (Fig. 1). In two of them (phenomenon II and III) heat transfer is thought to be boiling under crisis conditions, thus:

1. phenomenon II, characterized by the decrease in heat transfer coefficient, being the consequence of the appearance of vapour layer inside CPS $[3,4]$.

2. phenomenon III, characterized by the occurrence of a continuous vapour film outside the structure, $[3,5]$.

\footnotetext{
${ }^{1}$ - Kielce University of Technology, Dep. of Mechanics, Kielce, Poland (tmptw@tu.kielce.pl)
} 
The decrement of heat transfer coefficient value, accompanying phenomenon II is caused by the occurrence of the so-called "intralayer crisis". It is a process characteristic of porous coverings, which consists in vapour film creation inside the porous structure. The film isolates the heating surface from the remaining part of the covering flooded with a liquid. In the diagram, it is manifested as the characteristic change of the boiling curve inclination or in the occurrence of horizontal sectors of $\mathrm{q}_{\mathrm{kr}} *$ threshold values (Fig.2). Transitions are accompanied by high temperature increments.
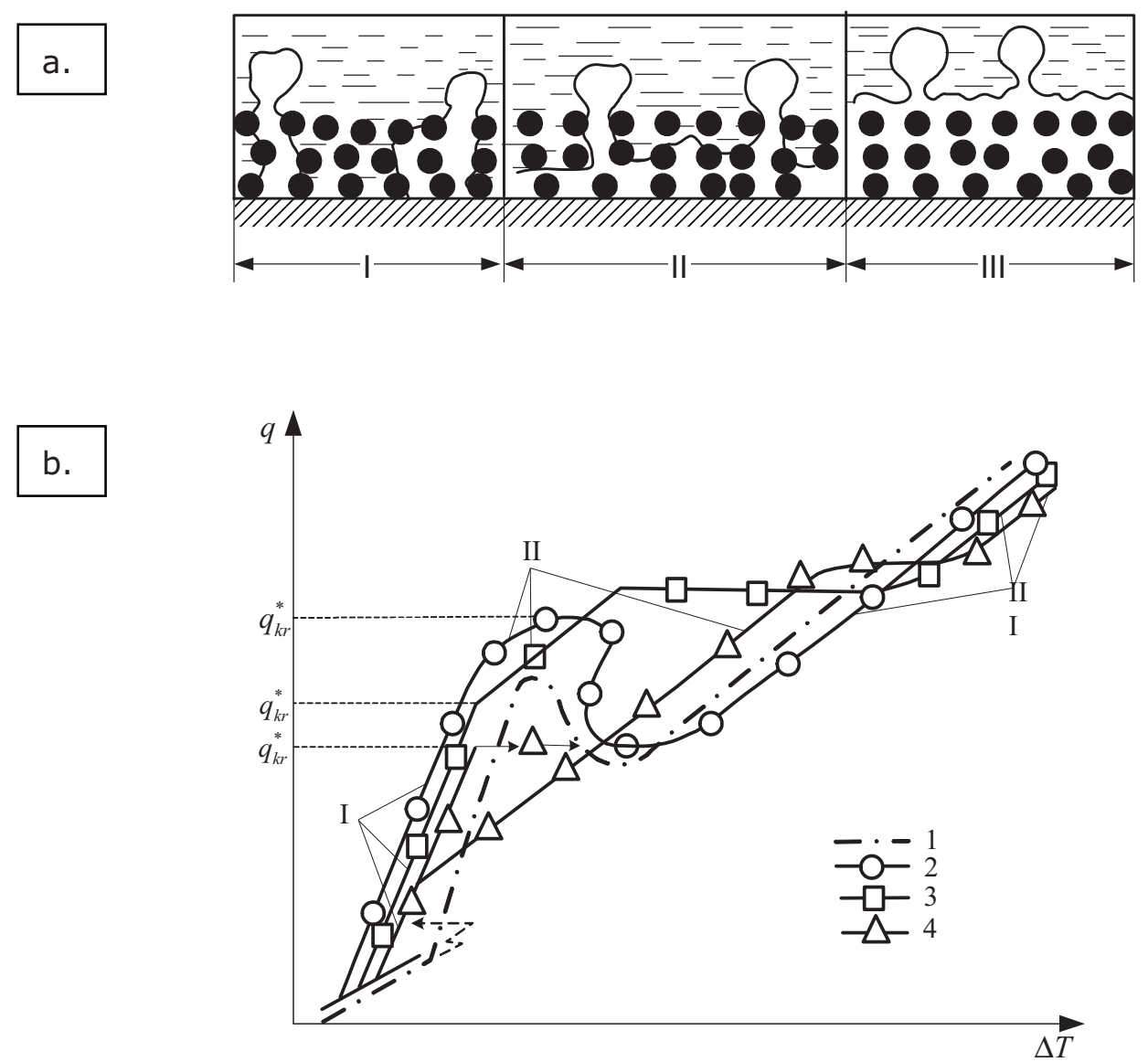

Fig. 1. a. Phenomena can be observed in porous layer boiling, $b$. shapes of boiling curves on a smooth surface (1) and the surface with capillary porous coverings (2), (3) and (4), [3]

A lot of authors assume that the boiling crisis starts only when the entire outer side of porous layer has been covered with a vapour film (phenomenon II, Fig.1). The appearance of a vapour film outside the porous covering induces the heating surface burnout in a short period of time (Fig. 3, [6]). 


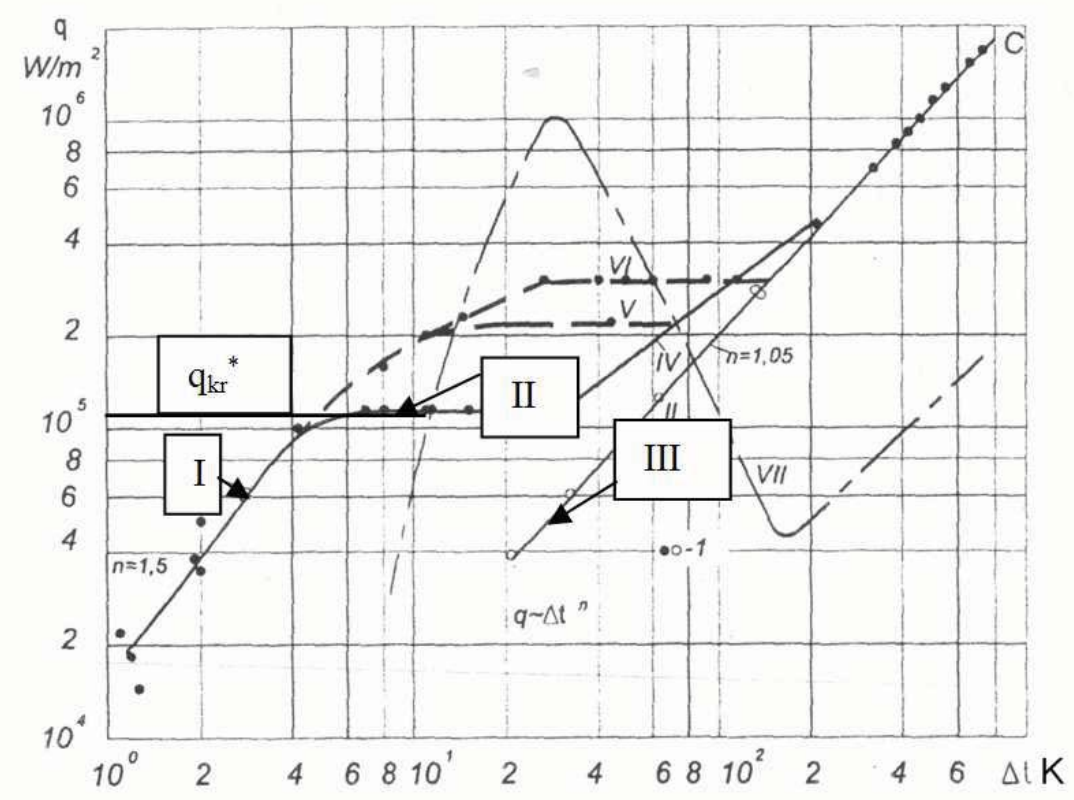

Fig. 2. Intralayer boiling crisis $\left(\mathrm{q}_{\mathrm{kr}}{ }^{*}\right)$, Afgan et al. investigations [5], sputtered structure

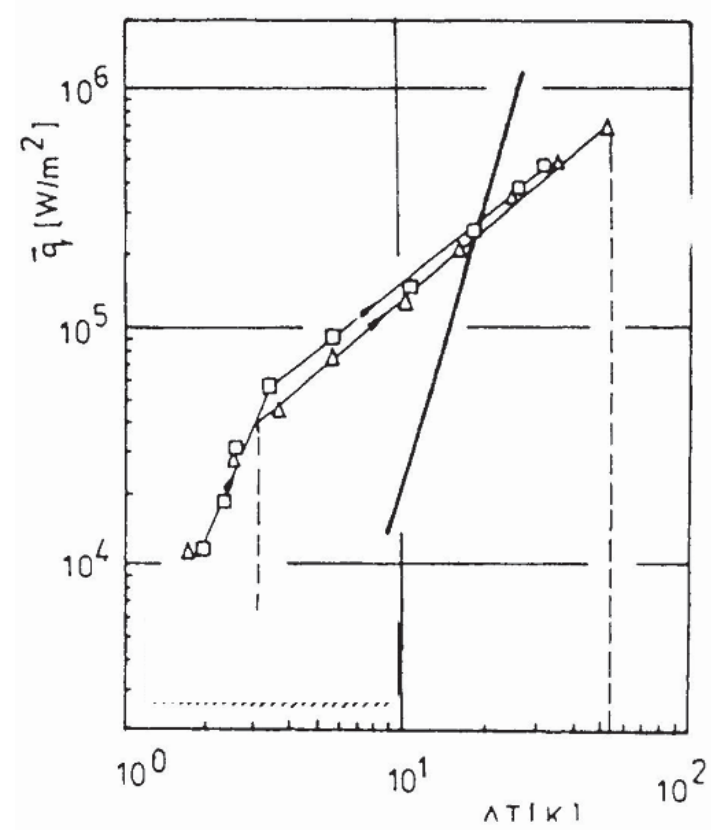

Fig. 3. Heating surface burnout as the effect of vapour appearance on the outer surface of porous covering, sputtered aluminium structure [6] 
The conclusions drawn from the literature review are that the flux critical value could be regarded as the one which initiates both the first and the second of the processes discussed above. The authors of the present paper believe that the minimum heat flux $\mathrm{q}_{\mathrm{kr}}{ }^{*}$, which starts intralayer boiling crisis should be considered to be the critical flux at porous layer boiling. The basic argument in favour of the above thesis is the inability for the equipment to function in a stable manner at changeable heat flux, after exceeding $\mathrm{q}_{\mathrm{kr}} *$. Although the heat transfer coefficient drop which occurs then, does not cause such violent temperature changes as in case of technically smooth surface („,burnout"), yet a given surface is excluded from work. Therefore, experimental and theoretical investigations, which aim at boiling modelling, seem indispensable.

\section{Aim AND Scope of the InVESTIGATIONS}

The aim of the paper was to carry out experimental and theoretical investigations into intralayer boiling heat transfer crisis in sintered, porous structures. The subject of research were copper porous structures widely applied in heat pipes. Experimental investigations concentrated mainly on the determination of structure parameters and boiling agents thermal properties, for which intralayer boiling crisis is revealed.
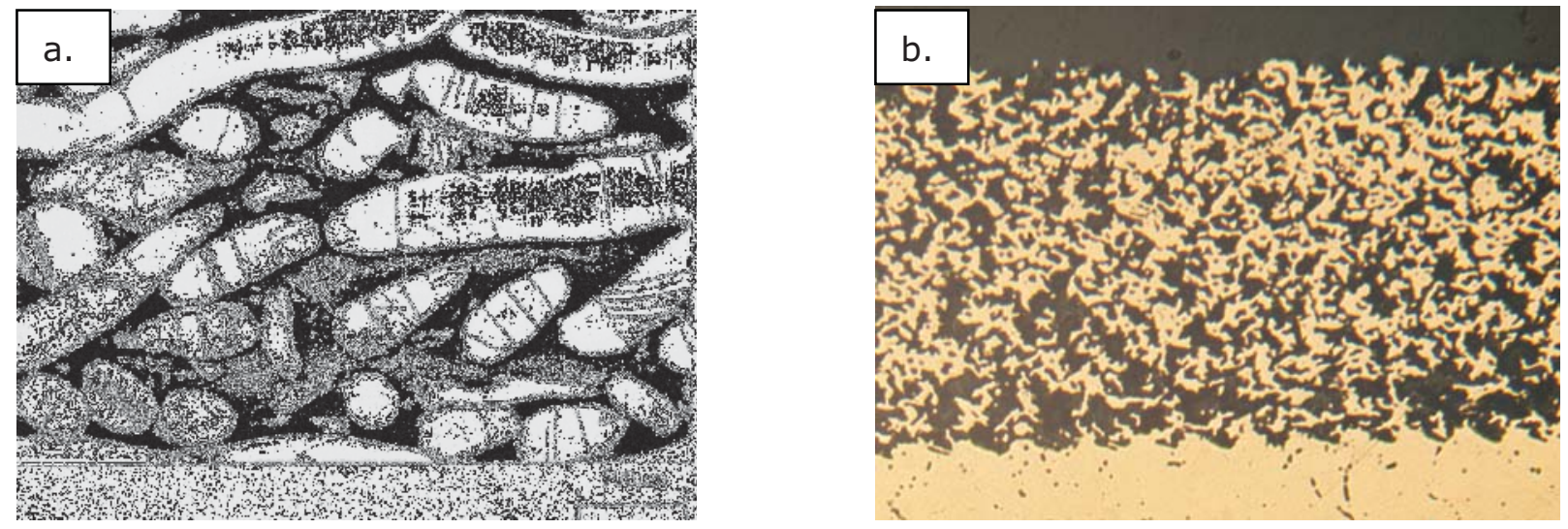

Fig. 4. Investigated samples: a. sintered fibrous structure, b. sintered $\mathrm{Cu}+\mathrm{CuO}_{2}$ powder structure

\section{EXPERIMENTAL STAND}

Fig. 5 present a diagram of the experimental stand and its basic module [7]..

A specimen (5a, Fig. 5) with a porous covering was mounted on a copper cylinder (5b). A heater wound around the cylinder (5c) was charged via autotransformer. The cylinder was thermally isolated with a ceramic pipe (5d) and insulation fillings. A compensation heater (5e) mounted on the exterior of the ceramic pipe (5d) provided additional protection against heat loss. Type $\mathrm{K}$ thermocouples (5f) were mounted underneath the specimen, on the axis of the cylinder and in the boiling liquid. The temperature of the heating surface was determined by extrapolating to it temperatures measured along the 
axis of the cylinder. The measurement error was $9 \%$ for temperature differences and $12 \%$ for the heat flux.

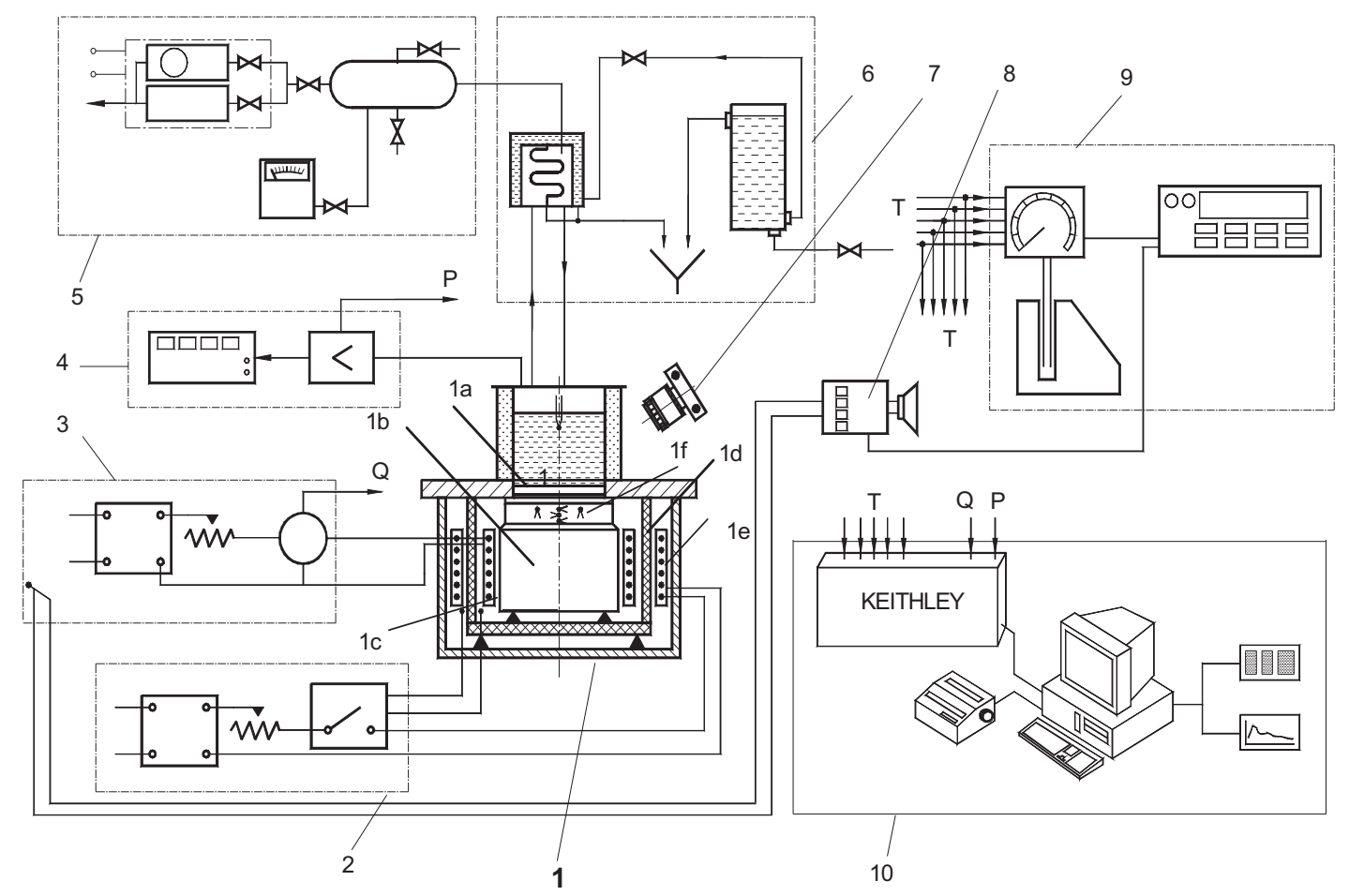

4.

Fig. 5. Diagram of the experimental stand and auxiliary systems: 1 - basic module; 2- heat loss compensation system; 3 - heating module with input power reading ; 4 - measurement of pressure in liquid tank; 5 - low pressure generating and measuring module; 6 - vapor cooling and condensate recovering module; 7 - digital high speed camera; 8 - excessive temperature signaling module; 9 - temperature measuring module; 10 - data collecting and processing module; $\mathbf{p}$ - pressure; $\mathbf{Q}$ - electric power; $\mathrm{T}$ - temperature

\section{Results}

Fig. 6 presented an example of intralayer crisis in metal fibrous porous coverings (curve 2). The intralayer boiling crisis is characterized by the appearance of horizontal boiling curve sectors, similarly to Fig. 2 and the first one is to be found at the flux $\mathrm{q}_{\mathrm{kr}}$ * threshold value. The phenomenon was observed for the structure of $40 \%$ porosity and $2 \mathrm{~mm}$ thickness at water boiling under atmospheric pressure. The flat curve indicates a clear drop in heat transfer coefficient. 
For coverings of smaller thickness, the same $40 \%$ porosity and water as the boiling agent, similar phenomena were not observed (curves 2 and 3, Fig.6) nor were they present in case of smooth surface (curve 1). After the flux value $\mathrm{q}_{\mathrm{kr}} * \sim 1.7 \cdot 10^{5} \mathrm{Wm}^{-2}$, (curve 2, Fig.6) is exceeded, there begins a steady, spontaneous surface temperature increase - range II. It is a slow process, the temperature increases at approx. $15 \mathrm{~K} / \mathrm{h}$.

If in the range II there occurs only a slight increase in delivered flux, but it has the form of a jump and later the new flux value is maintained - range III, the surface temperature will grow in an uncontrolled way and the rate of temperature changes will be higher than before. Heat transfer coefficient decrement in those ranges points to the formation of vapour layer inside the porous structure.

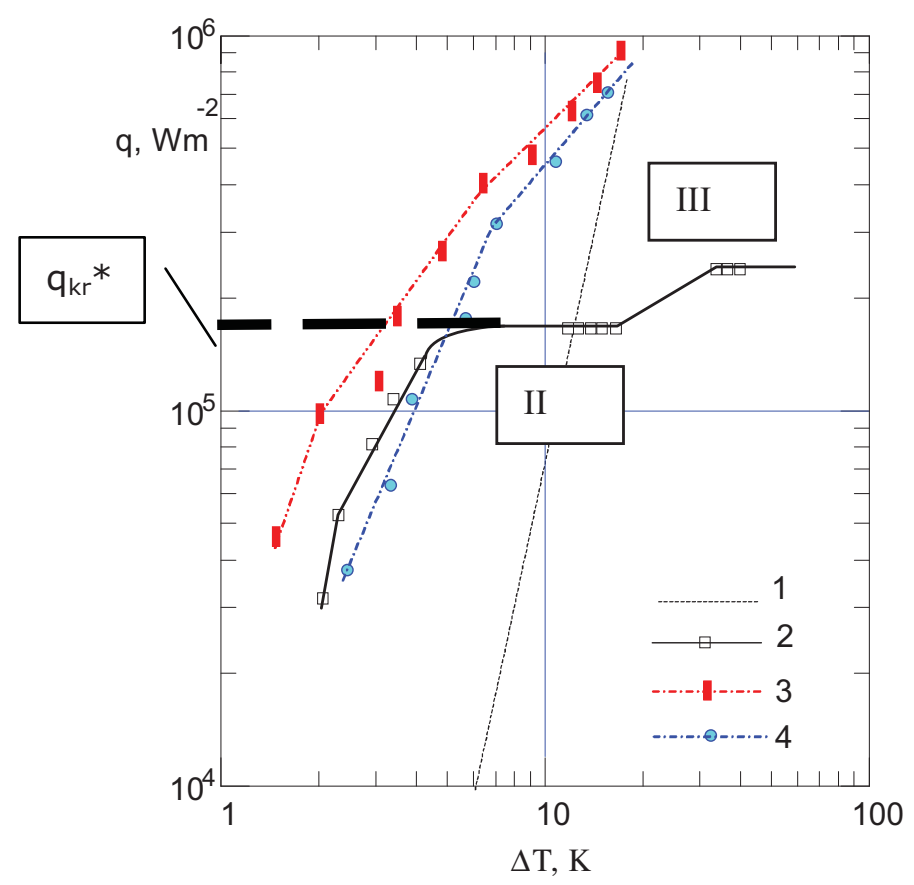

Fig. 6. The impact of porous covering thickness on the boiling curve shape, $\Pi=$ 40\%, water, atmospheric pressure:

1 - Smooth surface, copper (Rohsenov's curve)

2 - Copper fibrous CPS, $\delta=2.0 \mathrm{~mm}$

3 - Copper fibrous CPS, $\delta=0.6 \mathrm{~mm}$

4 - Copper fibrous CPS, $\delta=0.2 \mathrm{~mm}$ 


\section{Conclusions}

1. The complex mechanism of boiling heat transfer in porous structures is responsible for a number of peculiarities not observed on smooth surfaces, like intralayer boiling crisis or hysteresis phenomenon.

2. Heat flux $\mathrm{q}_{\mathrm{kr}} *$ which initiates intralayer boiling crisis should be regarded as the critical one with reference to heat transfer in porous layers.

3. Experimental investigations proved that the increase in the structure thickness induces intralayer crisis at lower heat fluxes.

4. The vapour appearance inside the porous covering and the difficulties in the drainage of it are responsible for I-kind hysteresis.

5. The complexity of boiling crisis in CPS justifies the choice of stochastic modelling.

\section{REFERENCES}

[1] Tehver Ja. H., Sui H. N.,Tiemkina W. S.: Zakipanije zidkosti na poristoj powierchnosti i gistieriezis tieploodaczi, Izw. AN Est. SSR, Fizika - Matiematika, no. 38, 1989, pp. 47

[2] Chowdhury S. K. R., Winterton R. H. S.I: Surface Effects in Pool Boiling, Int. J. Heat Mass Transfer, vol. 28, 1985, pp. 1881-1889

[3] Malyszenko S. P.: Osobiennosti tieploobmiena pri kipienii na powierchnostiach $\mathrm{S}$ poristymi pokrytijami, Tieploeniergietika, no. 2, 1991, pp. 38-44

[4] Lewtierow A. I., Semena M. G., Zaripow W. K. : Issledowanie tieploobmiena i kriticzeskich teplwych potokow pri kipienie azota na powierchnosti nagriewa $S$ poristymi pokrytijami,, Tieploeniergietika, No 4, 1982, pp. 66-69.

[5] Afgan N. H., Jovic L. A., Kowalew S. A., Lenikow V. A.: Boiling Heat Transfer from Surfaces with Porous Layers, Int. J. Heat Mass Transfer, vol.28, 1985, pp. 415-422

[6] Cieslinski J.T.: Studium wrzenia pecherzykowego na metalicznych powierzchniach porowatych, Zesz. Nauk. Politechniki Gdanskiej, Nr 547, Mechanika LXXIV , Gdansk,1996.

[7] Wójcik, T.M.:Experimental Investigations of Boiling Heat Transfer Hysteresis on Sintered, Metal - Fibrous, Porous Structures, Exp. Thermal and Fluid Sc., Vol. 33, 2009, pp. 397-404 